\title{
A escrita do corpo: Poemas eróticos de Florbela Espanca e Gilka Machado
}

\section{Jussara Neves Rezende ${ }^{1}$}

RESUMO: No início do século XX, em Portugal e no Brasil, respectivamente, Florbela Espanca e Gilka Machado criam versos em que dão voz à sensualidade feminina, enfatizando o corpo como o lugar em que as paixões se embatem. Além de refletir sobre os modos poéticos com que o erotismo se manifesta nas obras destas poetisas, este trabalho busca similaridades e diferenças que ampliem o que se sabe sobre a poesia feminina e valorizem a individualidade de cada escritora e de sua obra.

ABSTRACT: At the beginning of the XX century, Florbela Espanca and Gilka Machado, in Portugal and in Brazil, respectively, create verses in which they give voice to the feminine sensuality, by emphasizing the body as the place where the passions collide. This essay argues on the poetic ways in what the erotism itself becomes manifest in the works of theses poetess, besides searching into similarities and differences that broaden the limits of what is known about the feminine poetry, as well as to value the individuality of each writer and their works.

PALAVRAS-CHAVE: Florbela Espanca; Gilka Machado; erotismo; poesia.

KEYWORDS: Florbela Espanca; Gilka Machado; erotism; poetry.

A origem de Eros, nascido no jardim dos deuses após um grande festim, fruto da união de Poros (Recurso) e Pênia (Pobreza), determina, segundo Sócrates - último interlocutor dos seis discursos de banquete $^{2}$ - a inquietude e a insatisfação que o levam a incessantemente perseguir, como Pobreza que é, o que lhe falta, ainda que, como Recurso, saiba exatamente os meios para atingir seu objetivo. Este sentido se casa ao pensamento de Georges Bataille ${ }^{3}$ sobre o erotismo, pois segundo este autor há entre os seres "um abismo, uma descontinuidade", em razão de todos os seres serem distintos uns dos outros. Na reprodução, quando os seres descontínuos se unem, se estabelece pela fusão entre eles uma continuidade, independente de sua diferença. Essa continuidade, no entanto, instituída na geração de um novo ser, é interrompida com o nascimento e, ironicamente, o novo ser trará em si a "nostalgia da continuidade perdida" e tentará durante sua existência, alcançar o sentimento de continuidade que poderá substituir sua descontinuidade e isolamento. O erotismo seria, assim, essa busca pela

\footnotetext{
${ }^{1}$ Doutora em Estudos Comparados de Literaturas de Língua Portuguesa, FFLCH-USP. Pesquisa: $A$ simbolização nas imagens poéticas de Cecília Meireles e Sophia de Mello Breyner Andresen: tempo e espaço. E-mail: jussaraneves@hotmail.com

${ }^{2}$ PLATÃO, 2001, p. 143-5.

${ }^{3}$ BATAILLE, 1987, p. 12-23.
} 
continuidade, pela completude, em cujas bases se encontra o mesmo sentido de insatisfação referido em $O$ banquete, responsável pela inquietude de Eros.

Nos poemas de Florbela e Gilka nota-se que a manifestação do erótico se dá justamente quando é clara a insatisfação do eu-lírico em seu isolamento, o que o leva a crer que na fusão com o amado alcançará a desejada sensação de completude. Assim, é que nos versos de Florbela um descontínuo eu se oferece ao amor, enquanto Gilka canta os excessos da fusão amorosa ou rememora os momentos em que ela se deu, privilegiando ambas, os idealizados ou vividos momentos de paixão que conferem ao ser o sentimento da almejada continuidade.

Nascidas no final do século XIX, com menos de dois anos de diferença ${ }^{4}$, e separadas pelo Atlântico, Florbela e Gilka marcam as literaturas de expressão portuguesa ao exprimirem a voz da mulher, evidenciando o seu modo de pensar e sentir e transformando em matéria poética o ato amoroso.

Enquanto a época exigia um discurso poético "bem comportado", imposto pelas condições sociais e pelo momento histórico, pois até poetar era um desafio para a mulher nesse período, as duas poetisas transformam o desejo e a fruição erótica em poesia, ainda que, como se percebe em Florbela, o amor poetizado seja mais sonhado que real, ou, como no caso de Gilka, ainda que real tenha chegado ao fim.

Colocar em versos as suas idéias representou, para a mulher, uma vitória de anos de luta. Antes foi preciso dominar a palavra escrita. Depois, conviver com o preconceito da sociedade que acreditava ser prerrogativa masculina a atividade de criação. Além do preconceito referente ao sexo, existiam as cobranças quanto ao que era escrito e quanto à forma como escreviam. A época valorizava a erudição, mas a educação oferecida às mulheres, quando oferecida alguma, era diferenciada da dos homens. O acesso aos cursos superiores apenas começava a ser conquistado por algumas poucas, o que tornava difícil fugir dos lugares-comuns e dos temas convencionais que também se explicavam pelo fato de que as únicas leituras a que as mulheres tinham acesso eram os romances "água-com-açúcar", ao passo que os homens, recebiam esmerada educação.

No entanto, contra todas as perspectivas, muitas mulheres escreveram no alvorecer do século XX. Quando Florbela e Gilka começam a publicar, eram comuns os chás literários em que se declamavam poemas, muitos deles promovidos por senhoras. Mas enquanto da Europa se espalhavam para as Américas as idéias da Nova Mulher,

\footnotetext{
${ }^{4}$ Gilka nasceu em 12.03.1893 e Florbela em 08.12.1894.
} 
educada, que ocupava espaço considerável no mercado de trabalho e sexualmente livre, vozes da tradição se erguiam procurando valorizar a antiga mulher, voltada para a maternidade ${ }^{5}$.

Falar do próprio corpo talvez tenha sido a forma encontrada pela mulher para se posicionar no mundo e, entendendo-se como pessoa, exprimir suas experiências e revelar a natureza dos seus sentimentos. A própria índole feminina, segundo observa Zelita Seabra ${ }^{6}$, faz com que sua vida "corra, escoe, deslize muito perto das coisas", cabendo-lhe, portanto, o fruir, o gozar daquilo que se oferece aos seus sentidos. É possível que por essa razão a escrita feminina esteja sempre vinculada ao erótico, a ponto de alguns estudiosos afirmarem que a linguagem feminina é essencialmente erotizada.

Se o erotismo é tema recorrente na literatura feminina, na poética de Florbela e Gilka é sem dúvida "determinante”, como percebe Lucia Castello Branco ${ }^{7}$.

A leitura dos poemas de Charneca em flor (1931), de Florbela, faz vibrar uma voz que, identificada como sendo feminina, insinua-se por caminhos que à mulher não era dado percorrer à época em que foram escritos. Porque essa voz ousa enveredar-se por tais sendas e oferecer-se ao amor, chocando-se com os modelos oficiais de mulher então vigentes, é que se torna possível identificá-la a uma manifestação do erotismo. Embora latente nas primeiras produções da autora, em Charneca em flor o erotismo irrompe "transbordante" $"$, opondo-se à imagem contida da monja que Florbela delineara anteriormente.

O eu-lírico de Meu glorioso pecado (1928), livro de Gilka, é, por outro lado, voz que se ergue para dizer da paixão e dos reflexos dessa paixão no corpo, a partir de impressões sensoriais a que a autora, desde suas primeiras produções, sempre esteve atenta, fruto de sua formação poética numa época impregnada dos processos sinestésicos dos simbolistas. Se em suas primeiras publicações a preocupação da poetisa parece se voltar para o uso dos sentidos como forma de percepção do mundo, em $\mathrm{Meu}$ glorioso pecado os sentidos servem para perceber o amado e amante, dono de olhos que sugerem maciezas e doçuras, provocando-lhe, por sua proximidade, reações que se assemelham ao estado de embriaguez. Contudo, essa voz que se ocupa da paixão apresenta-se dividida entre o prazer que entontece e a culpa pela vivência desse prazer, o que reflete a condição paradoxal da mulher, marcada pela busca da liberdade e pela

\footnotetext{
${ }^{5}$ TELLES, 1997, p. 403.

${ }^{6}$ SEABRA, 1987, p. 56.

${ }^{7}$ BRANCO, 1989, p. 90.

${ }^{8}$ DAL FARRA, 1997, p. XLIII-XLIV.
} 
convivência com valores tradicionais. Tal contradição, já anunciada pelo próprio título do livro, marca os versos de Gilka, dosando-lhe a volúpia e a audácia.

Numa época em que o soneto era moda, as duas escritoras se servem dessa forma tradicional para expressarem o turbilhão de emoções represadas em seu íntimo e revelarem o seu prazer ou desprazer, o seu recato ou sua ousadia e os reflexos, no corpo, dos momentos idealizados ou vividos de paixão. A forma sempre fixa do soneto, em Florbela, parece o meio encontrado pela autora para equilibrar-se e para cercar com segurança a expressão passional de seu universo interior. Em Gilka, a pacífica convivência entre sonetos e poemas de versos livres e brancos, talvez só seja possível por tratarem os sonetos de um conteúdo totalmente novo se comparado ao que era peculiar aos poemas com essa forma fixa.

Uma das formas de o erotismo se manifestar na poesia de Florbela é através dos retratos que ela tece de si mesma para ofertar ao amado e fazer-se para ele desejável, convocando-o mesmo, em alguns versos, ao amor, iniciativa bastante imprópria para a mulher na época da escritora. A pintura minuciosa de seus traços físicos imprime à obra de Florbela o caráter sensorial que a identifica, refletindo-lhe o temperamento "ardente, idealista e sensual"9 e até mesmo a disposição da poetisa de, ao retratar-se sensualmente, romper com as convenções ${ }^{10}$.

Em "Passeio ao campo", a seguir transcrito, a expressão "Colhe a hora que passa", que se segue aos vocativos usados no primeiro verso para atrair a atenção do amado, é clara referência ao carpe diem, confirmando que Florbela transpõe para o feminino o topos do poeta que chama a amada para viverem nos campos o amor. No poema em questão, não só a feminilidade do eu está claramente marcada ("Sou menina!"), quanto a variação no uso dos vocábulos que evocam o amado (Amor/Amante/Amigo) e o próprio convite que lhe é feito lembram a forma com que as moças das cantigas de amigo medievais se dirigiam aos namorados:

Meu Amor! meu Amante! Meu amigo!

Colhe a hora que passa, hora divina,

Bebe-a dentro de mim, bebe-a comigo!

Sinto-me alegre e forte! Sou menina!

Eu tenho, Amor, a cinta esbelta e fina...

Pele doirada de alabastro antigo...

Frágeis mãos de madona florentina...

- Vamos correr e rir por entre o trigo! -

\footnotetext{
${ }^{9}$ FREIRE, 1977, p. 22

${ }^{10}$ ALONSO, 1997, p. 175.
} 
Há rendas de gramíneas pelos montes...

Papoilas rubras nos trigais maduros...

Água azulada a cintilar nas fontes...

E à volta, Amor... tornemos, nas alfombras

Dos caminhos selvagens e escuros,

Num astro só as nossas duas sombras!...

O apelo feito ao amado nos versos iniciais, para que seja aproveitada, colhida, "a hora que passa", torna-se um convite abertamente sensual no verso 3, quando convida-o para beber dentro de si e consigo a hora fugidia, chamando-a mesmo de "divina", o que estabelece uma ligação, comum em Florbela, entre erótico e sagrado.

A autocaracterização da mulher nestes versos, através da qual esta se apresenta como objeto de desejo, inicia-se no quarto verso, com a valorização de seus atrativos, e continua na segunda quadra com a descrição de sua cintura, pele e mãos. As referências ao "alabastro antigo" e à "madona florentina" parecem querer sugerir que é clássica a beleza da mulher aí descrita, lembrando uma antiga escultura ou uma tela do renascimento italiano ${ }^{11}$.

Referidos os seus atributos, o eu reitera no oitavo verso o convite ao amor e passa a descrever, no primeiro terceto, a exuberante natureza que o rodeia e que, por sua fertilidade, pois estão floridos os montes, maduros os trigais e as fontes cintilam, parece lembrar que o tempo é propício ao amor. A descrição da fértil natureza funciona como uma confirmação do convite já feito que fica ainda mais explícito, no segundo terceto, com a fusão das "duas sombras" num só astro, metáfora que revela o desejo de contato físico que sente a mulher que propõe o passeio ao campo e, ao mesmo tempo, sua visão do amor como luz suficiente para elidir a escuridão. A natureza, nos versos de Florbela, é quase sempre, como nos versos em estudo, metáfora do corpo e da sensualidade.

O embrião do procedimento literário que consiste em fundir sinais de uma oferta sensual a um convite para um passeio ao campo, onde será possível “correr e rir por entre o trigo", encontra-se, provavelmente, nas cantigas de amigo medievais. Talvez seja possível, no entanto, pensar tal procedimento como vindo de mais distante no tempo, uma vez que não só o passeio pelo campo, mas a descrição física que valoriza o eu-lírico, lembra a Esposa do Cântico dos cânticos, de Salomão ${ }^{12}$, que não apenas tem

\footnotetext{
${ }^{11}$ Id., p. 183.

${ }^{12}$ Cântico dos Cânticos, Caps. 1:5-12; 2: 1; 7:11-12; 8: 10. In: A Bíblia Sagrada.
} 
seus traços valorizados pelo homem que ama, como também os valoriza, incitando-o ao amor:

Eu estou morena e formosa,

ó filhas de Jerusalém.

o meu nardo exala o seu perfume.

Eu sou a rosa de Sarom,

o lírio dos vales.

Vem, ó meu amado,

saiamos ao campo,

passemos as noites nas aldeias.

Levantemo-nos cedo de manhã

Para ir às vinhas;

vejamos se florescem as vides,

se se abre a flor,

se já brotam as romeiras,

dar-te-ei ali o meu amor.

Eu sou um muro,

E os meus seios, como as suas torres.

Tanto em Salomão, porém, quanto nas cantigas medievais, é um homem que escreve fingindo um sentimento feminino, enquanto em Florbela encontra-se a autêntica expressão de um desejo feminino de contato amoroso, o que faz com que sua poesia, ainda que não fosse esta sua intenção, quebre as regras do pacto social ao colocar em palavras expectativas não condizentes com os papéis culturais oferecidos à mulher na época em que viveu.

Em Gilka, a principal característica do erotismo talvez consista na rivalidade existente entre o corpo e a alma do $e u$ que se movimenta em direção ao outro, o que indica que se sente dividido entre o desejo e a negação dele.

No fragmento a seguir, do poema "Há lá por fora um luar", a divisão do ser é exposta numa seqüência de versos repletos de paradoxos:

Há lá por fora

um luar

que é um divino pecado...

Se viesses, meu amado,

se surgisses agora

ao meu olhar,

se me apertasses, trêmula de susto,

ao teu formoso busto...

Não é noite nem dia,

observo, com surpresa, 




(p. 268-9)

O "romântico emblematismo da natureza"13 é o alicerce, no poema, das imagens que desenham a mulher dividida entre o pecado e o prazer. Porque "lá por fora" o luar é um "divino pecado", é que o eu do poema se põe a desejar a presença do amado para "agora", para a vivência do gozo que o seu corpo "amado e amante" anseia. Esse amor, porém, que repele o outro e o quer na mesma intensidade (versos 21 e 22), indica que a mulher desenhada nos versos encontra-se tão dividida quanto "a natureza" que, imersa em "triste alegria", espalha paradoxos "no ar".

Em si mesma a mulher reúne em "dolorosa orgia", "prazer" e "tortura", "alegria e tristeza", "ódio e paixão", sentindo como pecado ("a alma peca") o desejo que a toma e que a faz sonhar com o abraço do amado. Por esta razão a vivência das palpitações do "gozo" fica nos domínios do sonho ("fugindo-te e sonhando"), espaço em que a mulher pode ousar e participar ativamente do encontro amoroso. Nos primeiros versos do poema a repetição da condicional se, indica tratarem-se de conjecturas todos os versos seguintes.

Quanto ao encontro amoroso cantado por ambas as poetisas, percebe-se maior realidade nos versos de Gilka. É nos domínios do sonho que se dão grande parte dos encontros amorosos descritos por Florbela. O soneto "A nossa casa" é exemplo disto e nele o erotismo se manifesta pela revelação do desejo de contato físico que sente o $e u$ do discurso:

A nossa casa, Amor, a nossa casa!

${ }^{13}$ SOARES, 1999, p. 106. 
Onde está ela, Amor, que não a vejo?

Na minha doida fantasia em brasa

Constrói-a, num instante, o meu desejo!

(p. 224)

Os dois primeiros versos situam a realidade do eu-lírico de não possuir com o outro uma vida em comum, uma casa que pudessem dividir e chamar "nossa". A exclamação usada no primeiro verso parece servir para despertar esse outro e fazê-lo participar da estupefação que sente o eu por não enxergar nos domínios do real a casa que ocupa seus sonhos (verso 2).

Se o real não oferece a realização do desejo, os versos 3 e 4 informam que o eu opta pela construção da casa através de sua "doida fantasia", sendo o construtor o próprio desejo. Isto valoriza o sonho que ocupa os tercetos:

Sonho... que eu e tu, dois pobrezinhos, Andamos de mãos dadas, nos caminhos Duma terra de rosas, num jardim,

Num país de ilusão que nunca vi...

O contato entre "eu e tu" se dá, como era de se esperar, num "país de ilusão" que o eu-lírico afirma nunca ter visto. Ali, embora sejam "dois pobrezinhos", eu e $t u$ têm a grande riqueza de poderem andar de "mãos dadas" por caminhos floridos. Ali, nesse lugar de sonho, "terra de rosas" ou "jardim" (nota-se que idealiza-se como belo o lugar onde se dará o encontro amoroso), é que encontra-se a sonhada "casa":

É que eu moro - tão bom! - dentro de ti

E tu, ó meu Amor, dentro de mim...

Continuando a idéia desenvolvida a partir do primeiro verso do primeiro terceto ("Sonho..."), os dois versos finais informam que faz parte do sonho o contato físico que é apresentado através do verbo morar. Morar um dentro do outro é, afinal, a essência do sonho do eu-lírico.

A ênfase dada ao prazer que esse contato, ainda que em sonhos, oferece (note-se a exclamação "tão bom!” realçada pelos travessões), explica a inicial afirmação (no terceiro verso) de que é "doida" e queima ("em brasa") a fantasia gerada pelo desejo. Revela, além disso, que o eu-lírico não teme patentear sua ânsia de intimidade amorosa.

Em Gilka, a grande ênfase dada ao corpo da mulher e às sensações por ele experimentadas no contato amoroso, foi revolucionária na época em que surgiram, 
quando a sociedade pretendia que o lar encerrasse a mulher, seus pensamentos e tudo que sobre ela pudesse ser pensado. Os versos de Gilka, porém, demonstram a inutilidade da coerção social, apontando a vivência da liberação do corpo, ainda que pela escrita, como forma de autodescobrimento e de descobrimento do mundo, de forma que sua individualidade possa ser respeitada e sua igualdade de direitos garantida. Neste sentido, a mulher posiciona-se em vários poemas como amada e amante, demonstrando, como veremos a seguir, que se submete ao amor do outro, mas é ainda sujeito da ação do próprio amor:

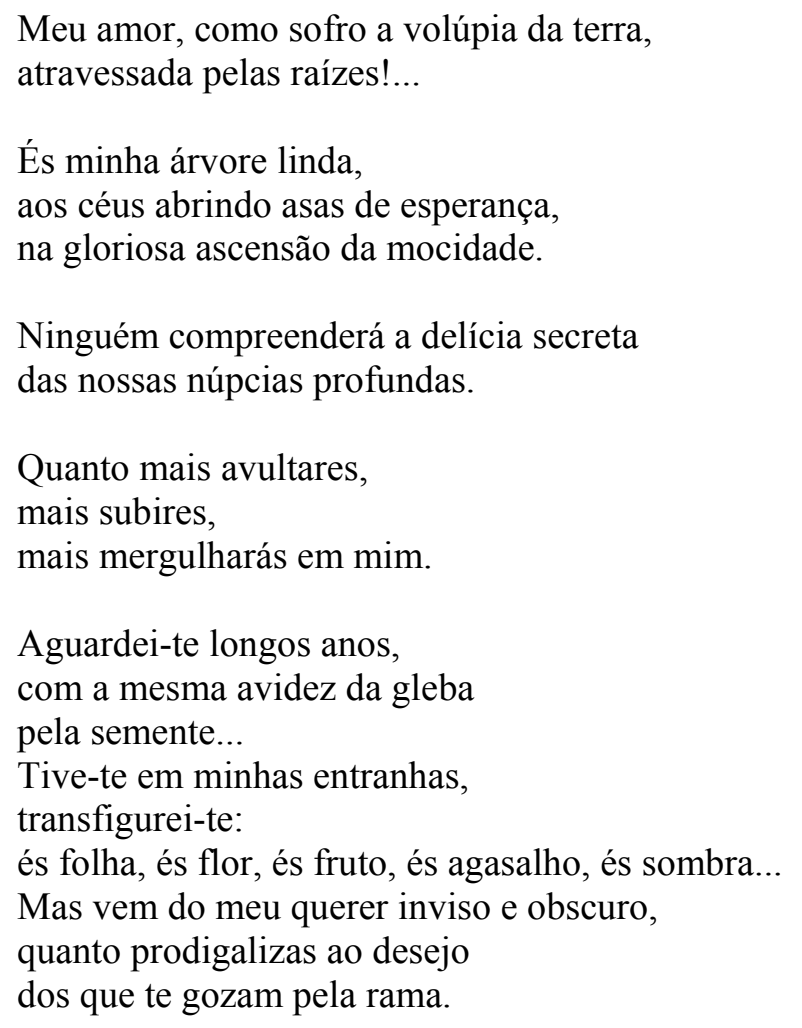

(p. 308)

Metaforizando-se como "terra", a mulher presente nos versos assimila como sua a mesma "volúpia" daquela que se sente "atravessada pelas raízes!...", o que inicia a composição do encontro erótico e do gozo feminino dele advindo. Este desenho do momento do contato amoroso prossegue com a exaltação da figura do amado, ressaltando-lhe não apenas as características físicas, como beleza e juventude ("árvore linda", "ascensão da mocidade"), mas ainda, na última estrofe citada, suas qualidades espirituais como "agasalho" e "sombra".

$\mathrm{Na}$ quarta estrofe, ressalta-se o excesso erótico que mobiliza os amantes a buscarem a sonhada completude. Isso se evidencia pelo uso dos advérbios "Quanto" e "mais", servindo a repetição deste último justamente para realçá-lo e ampliar a idéia de 
intensidade no contato amoroso. Além disso, o uso dos verbos "avultares" e "mergulharás", sugere o contato dos corpos entregues à vivência erótica. Estabelecendo o “jogo dialético entre elevação e penetração” percebido por Angélica Soares ${ }^{14}$. Ampliase desta forma, segundo a estudiosa, ao se ampliar o afastamento entre os corpos, a própria "intensidade do gozo", "uma vez que este afastamento será promotor de um mergulho mais profundo, de uma conexão mais completa”.

Na seqüência do poema este "jogo dialético" também se fará presente por meio da figura do "pássaro de vôos cativos" a quem a mulher apela para que suba mais e sempre, ao mesmo tempo em que mais o possui:

A árvore é bela quando a terra é boa...

A árvore é tão da terra quanto o sonho

é da carne que o gera.

Meu lindo pássaro de vôos

cativos,

sobe mais, sobe sempre!

- És muito meu!

São meus os braços enleantes

dos teus abraços interiores,

é na minha alma dilacerada

que o polvo de tuas artérias

suga a seiva do orgulho,

a energia do surto.

(p. 309)

Nota-se no primeiro verso dessa segunda parte do poema, uma referência do eulírico à própria potencialidade sexual, o que o uso das reticências ajuda a sugerir. A árvore/homem é bela tão somente porque a terra/mulher é boa, idéia que coloca em termo de igualdade os amantes e acaba por confundi-los, nos seis versos finais, onde "meus" e "teus", "braços" e "abraços" se misturam.

Lúcia Castello Branco ${ }^{15}$ refere-se à Florbela e Gilka como "desvairadas de seu tempo" e menciona a ousadia de ambas por se declararem, "sem qualquer recato literário", "no cio". Como escreveram na mesma língua e o tempo em que viveram foi o mesmo, marcado pelas mesmas correntes estéticas e literárias e por padrões morais e comportamentais similares, a leitura das obras das duas autoras denota os profundos liames que as permeiam.

Embora as duas autoras partam de pontos de vista próprios e por isso diferenciados, percebe-se ao longo de suas obras que a busca amorosa empreendida de

\footnotetext{
${ }^{14}$ Id., p. 112.

${ }^{15}$ Op. cit., p. 87-8.
} 
forma ousada em seus versos é direcionada pelo desejo de completude e não propriamente pela sexualidade em si. Florbela e Gilka parecem buscar na almejada fusão com o outro, a fusão com o próprio universo ou com o absoluto, o que as leva a se referirem aos respectivos objetos de desejo como "Amor", "Amado", "Alguém”, quase sempre com iniciais maiúsculas, evidenciando que o outro com quem se relacionam, ou almejam relacionar-se, equivale a um Outro que é visto como capaz de conferir ao ser a plenitude.

No encontro amoroso cantado por Gilka, é bastante evidente a "paixão da entrega", como observa Nelly Novaes Coelho ${ }^{16}$, enquanto em Florbela a "volúpia de amar (...) está mais próxima do narcisismo", do desejo de ser "admirada", "endeusada".

Ao reconhecer o caráter sagrado do erotismo, Florbela distingue-se de Gilka que demonstra ainda se preocupar com os padrões sociais nos quais não se enquadra.

Apesar da proposta textual de experimentar o amor como um fim em si, a maior parte dos sonetos de Charneca em flor fala mesmo é das tentativas de Florbela para conseguir o amor do homem que deseja, ou do seu sentimento de insatisfação por não tê-lo, ao passo que Gilka, em Meu glorioso pecado, embora evidencie o amor realizado em inúmeros poemas, acaba por cantar a perda desse amor.

Em ambas, o amor é ansiosamente procurado como forma de preencher um vazio que nunca se preenche, como se a vida, segundo a lição de Georges Bataille ${ }^{17}$, para se perpetuar, exigisse mesmo o encontro com esse amado fugidio.

\section{Referências bibliográficas}

A BÍBLIA SAGRADA. Trad. de João Ferreira de Almeida. 2a . Ed. São Paulo: Sociedade Bíblica do Brasil, 1993.

ALONSO, Cláudia Pazos Alonso. Imagens do eu na poesia de Florbela Espanca. Lisboa: INCM, 1997.

BATAILLE, Georges. O erotismo. $2^{\mathrm{a}}$ ed., Trad. de João Bernardo da Costa. Lisboa: Moraes, 1980.

BRANCO, Lúcia Castello, As incuráveis feridas da natureza feminina. In: BRANCO, L. C., BRANDÃO, R. S.. A mulher escrita. Rio de Janeiro: Casa-Maria Editorial, 1989, p.87-109.

COELHO, Nelly Novaes. O corpo-da-escrita no romance feminino português. Comunicação apresentada no IV Congresso da ABRALIC, 1994.

DAL FARRA, Maria Lúcia. Florbela: um caso feminino e poético. In: ESPANCA, Florbela. Poemas. São Paulo: Martins Fontes, 1997, p. V-XLIV.

ESPANCA, Florbela. Charneca em flor. In: Poemas/ Estudo introdutório, organização e notas de Maria Lúcia Dal Farra. São Paulo: Martins Fontes, 1996.

FREIRE, Antônio. O destino em Florbela Espanca. Porto: s. n. 1977.

\footnotetext{
${ }^{16}$ COELHO, 1994. Comunicação apresentada no IV Congresso ABRALIC.
}

${ }^{17}$ Op. cit.. 
MACHADO, Gilka. Meu glorioso pecado. In: Poesias completas. Rio de Janeiro: Léo Christiano Editorial Ltda., 1992.

PLATÃO. Banquete. Trad. de Jean Melville. São Paulo: Martin Claret, 2001.

REZENDE, Jussara Neves. "Charneca em flor" e "Meu glorioso pecado": nos domínios de Eros. São Paulo: FFLCH/USP, 2001. (Dissertação de Mestrado).

SEABRA, Z. Deméter e Perséfone: visão arquetípica da relação mãe e filha. In: SEABRA, Z., MUSZKAT, M. Identidade feminina. 3. ed. Petrópolis, RJ: Vozes, 1987.

SORAES, Angélica. A paixão emancipatória. Rio de Janeiro: Difel, 1999. 